\title{
FRONTAL POLYMERIZATION IN MICROGRAVITY
}

\author{
John A. Pojman \\ Department of Chemistry and Biochemistry \\ University of Southern Mississippi \\ Hattiesburg, MS 39406-5043 \\ (601) $266-5035 ; 6075 / \mathrm{fax}$ \\ john.pojman@usm.edu \\ www-chem.st.usm.edu/japgroup/JAPGROUP.html
}

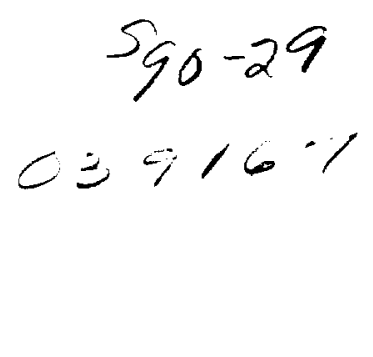

\section{Introduction}

Frontal polymerization is a mode of converting monomer into polymer via a localized reaction zone that propagates, most often through the coupling of thermal diffusion and Arrhenius reaction kinetics. Frontal polymerization reactions were first discovered in Russia by Chechilo and Enikolopyan in 1972.1 They studied methyl methacrylate polymerization to determine the effect of initiator type and concentration on front velocity ${ }^{2}$ and the effect of pressure. ${ }^{3}$ The literature up to 1984 was reviewed by Davtyan et al. ${ }^{4}$

Pojman and his co-workers demonstrated the feasibility of traveling fronts in solutions of thermal free-radical initiators in a variety of neat monomers at ambient pressure using liquid monomers ${ }^{5-7}$ and with a solid monomer. ${ }^{8}$ The macrokinetics and dynamics of frontal polymerization have been examined in detail ${ }^{9}$ and applications for materials synthesis considered. ${ }^{10}$

\section{Basic Phenomena}

Frontal polymerization reactions are relatively easy to perform. In the simplest case, a test tube is filled with the initial reactants. The front is ignited by applying heat to one end of the tube with an electric heater. The position of the front is obvious because of the difference in the optical properties of polymer and monomer. Figure 1 shows a typical front. Movies of all the phenomena described below can be viewed at our www site.

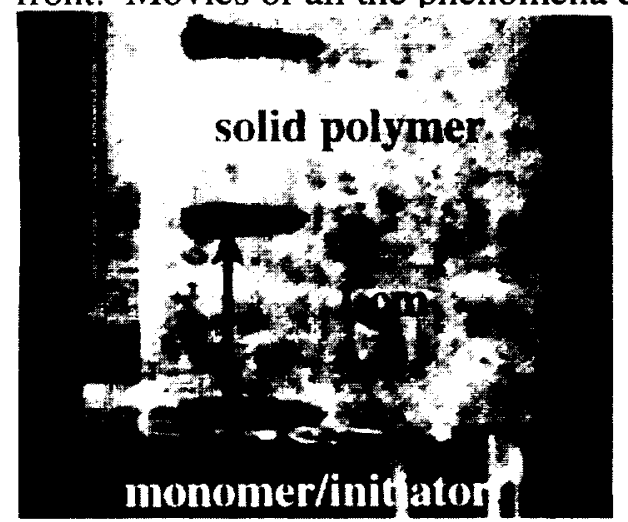

Figure 1. A descending case of frontal polymerization with triethylene glycol dimethacrylate and benzoyl peroxide as the initiator.

Under most cases, a plot of the front position versus time produces a straight line whose slope is the front velocity. The velocity can be affected by the initiator type and concentration but is on the order of a $\mathrm{cm} / \mathrm{min}$.

The defining feature of frontal polymerization is the sharp temperature gradient present in the front. Figure 2 shows three different temperature profiles for methacrylic acid for different initiators. Notice that the temperature jumps about $200^{\circ} \mathrm{C}$ over as little as a few millimeters, which corresponds to polymerization in a few seconds. 


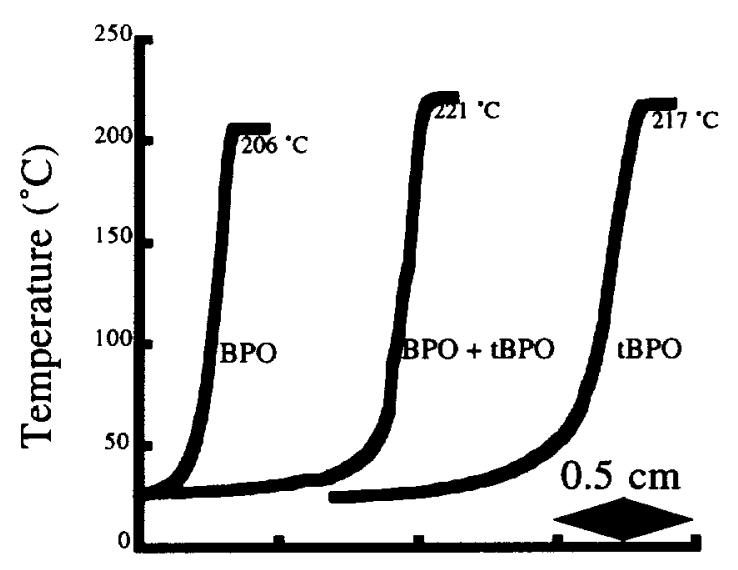

frontal interface (see Figure 1).

The second group of monomers form polymers that are insoluble in the monomer. Good examples are acrylic and methacrylic acids. ${ }^{5,7,11}$ Insoluble polymer particles adhere to each other during their formation and stick to the reactor or test tube walls, forming a mechanically durable phase and discernible polymer-monomer interface. How well the front sustains itself depends on conversion, the polymer glass transition temperature and molecular weight distribution.

The third group of monomers includes all highly reactive monomers that produce thermoplastic polymers, which are molten at the front temperature. Such fronts decay due to the Rayleigh-Taylor instability ${ }^{12,13}$ (Figure 3 ). Although these polymers are soluble in their monomers (given sufficient time), on the time scale of the front the polymer is effectively immiscible with the monomer. Adding an inert filler such as ultra-fine silica gel (Cabosil) increases the viscosity and eliminates the front collapse. However, adding a filler prevents the production of a homogeneous product. Some monomers like styrene and methyl methacrylate require moderate pressure (20-30 atm) to eliminate monomer boiling. Higher boiling temperature monomers like butyl methacrylate, butyl acrylate and benzyl acrylate support the frontal regime at ambient pressure in test tubes.

\section{Convective Instabilities}

In the early work on frontal polymerization, the authors ${ }^{1-3,14}$ applied very high pressure (up to $5000 \mathrm{~atm}$ ) to eliminate monomer (methyl methacrylate) boiling and the reaction zone decay due to the density gradient in the reaction zone (Rayleigh-Taylor instability) caused by the more dense polymer product overlying the unreacted monomer. They also managed to observe only downward traveling fronts because natural convection rapidly removed heat from the reaction zone of an ascending front leading to extinction. However, at pressures less than 1500 atm descending fronts decayed. 


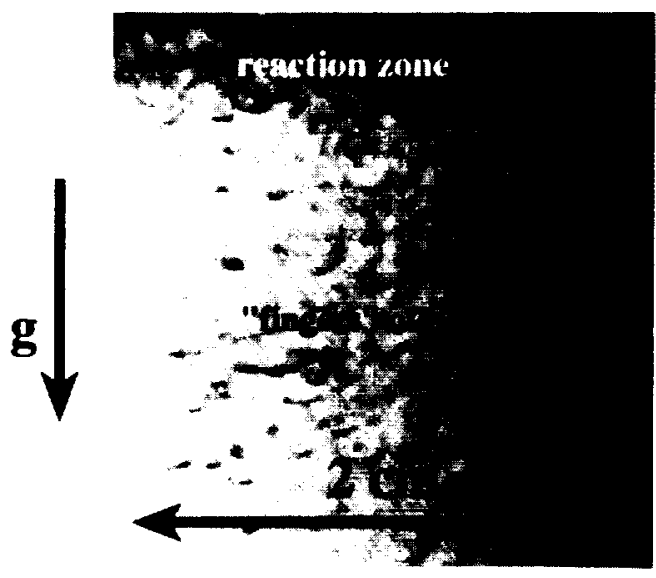

Figure 3. The Rayleigh-Taylor instability in a descending front of nbutyl acrylate polymerization.

Convection can occur with all types of monomers if the front propagates up a tube. Garbey et al. have analyzed the problem of convection in ascending frontal polymerization with a solid product and developed a modified Rayleigh number that predicts when the front will be unstable (convection will occur) and stable (front will be flat): ${ }^{15}$, 16

The theory predicts that for ascending fronts increased viscosity makes the front more stable with respect to convection, which is rather obvious. What is not obvious is that increasing the velocity of the ascending front also makes the front more stable. Because the monomer is converted to solid, if the front moves faster, then the liquid that is being heated is converted to product before it can move and appear as convection. These results were confirmed experimentally by Bowden et al. ${ }^{17}$

Recently, McCaughey et al. have confirmed the analysis of Garbey et al. ${ }^{15}$ for ascending fronts with a liquid product by observing that fronts could be stable if the viscosity were sufficiently high or the front velocity sufficiently rapid. ${ }^{18}$

Convection is a serious impediment for commercial applications of frontal polymerization. Chekanov et al. found that in the frontal curing of epoxy resin, ascending fronts were extinguished by convection. ${ }^{19}$

\section{Microgravity Experiments \\ Conquest I Sounding Rocket}

In order to study poly(n-butyl acrylate) fronts, Pojman et al. added fumed silica (CAB-O-SIL, Cabot Corp.) to increase monomer viscosity. ${ }^{20}$ However, the problem is that in increasing the viscosity of the medium could increase the molecular weight. The only way to determine the inherent molecular weight distribution that can be achieved in a front is to perform a front without CAB-O-SIL. Because of the Rayleigh-Taylor instability, the only way to accomplish this with n-butyl acrylate is to eliminate the driving force for the collapse of the more dense polymer layer, i.e., eliminate the force of gravity.

An experiment was launched on April 3, 1997 on the Conquest I rocket flight out of White Sands Missile Range under the Launch Voucher Demonstration Program, which was managed by the University of Alabama in Huntsville Consortium for Materials Development in Space. The flight provided at least 5 minutes of $10^{-4} \mathrm{~g}$ conditions.

Pojman et al. found that the molecular weight distribution of the sample polymerized in microgravity was very similar to the ground based-control experiment (Figure 4). ${ }^{21}$ Thus, the addition of a viscosity-enhancing agent does not significantly affect the molecular properties of the sample produced frontally. 

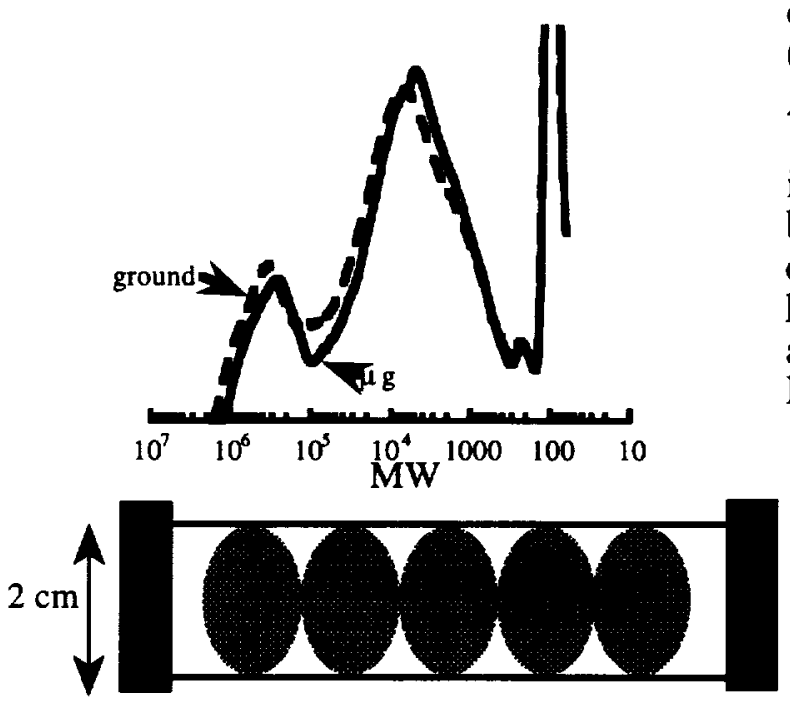

Figure 5. Approximate pattern of bubbles formed in front on Conquest 1 .

\section{$\underline{\text { KC-135 Flights }}$}

approximately 20 seconds of low $\mathrm{g}$ (about $0.1 \mathrm{~g}$ ) followed by a minute of $1-1.8 \mathrm{~g}$.

Benzyl acrylate (BzA) (Monomer-Polymer and Dajac) and triethylene glycol dimethacrylate (Aldrich) were used as received. Benzoyl peroxide (97\%, Aldrich) was used as the initiator with BzA, while Lupersol 231 (Atochem) was used with the TGDMA. We used $16 \times 125 \mathrm{~mm}$ tubes (VWR \#72690-022) on which a plastic cap (VWR \#60826290 ) could be securely screwed.

The reaction test tube was held snugly in a stainless steel mounting stand with the round sealed end of the test tube that fit into a cavity of the metal disk and the open end held by a polyethylene disk. The two disks were held together firmly with three stainless steel threaded rods. A cartridge heater was in contact with the sealed surface of the glass tube through a hole provided in the compression fitting and the metal disk. The 65 watt cartridge heater was energized with a 12 Volt DC power source for five minutes to trigger the reaction front. Because we were unable to observe the reaction in real time, we were not able to time the front to start at a specific stage of a parabola.

\section{Liquid/Liquid Fronts}

The rocket experiment indicated that bubbles can interact with the front. Because of the Rayleigh-Taylor instability discussed above, we can only study the interaction of bubbles with fronts of liquid polymer under weightless conditions.

Figure 6 shows how in weightlessness, the bubbles aggregate. When the high $g$ arrives, the bubbles rise to the top of the tube, and the molten polymer sinks. We propose that the bubbles move toward hotter the interior of the tube via surface-tension induced convection and aggregate as they do so.

\section{Liquid/Solid Fronts}

We repeated the experiment using triethylene glycol dimethacrylate, which forms a rigid crosslinked product. We deliberately left a bubble (about $0.5 \mathrm{~mL}$ ) when filling the tube to allow copious bubble formation. As bubbles are produced at the front in $1 \mathrm{~g}$, they 
form long strings of small bubbles (Figue 8). It seems that existing bubbles acts as a nucleation sites for further bubbles formation.

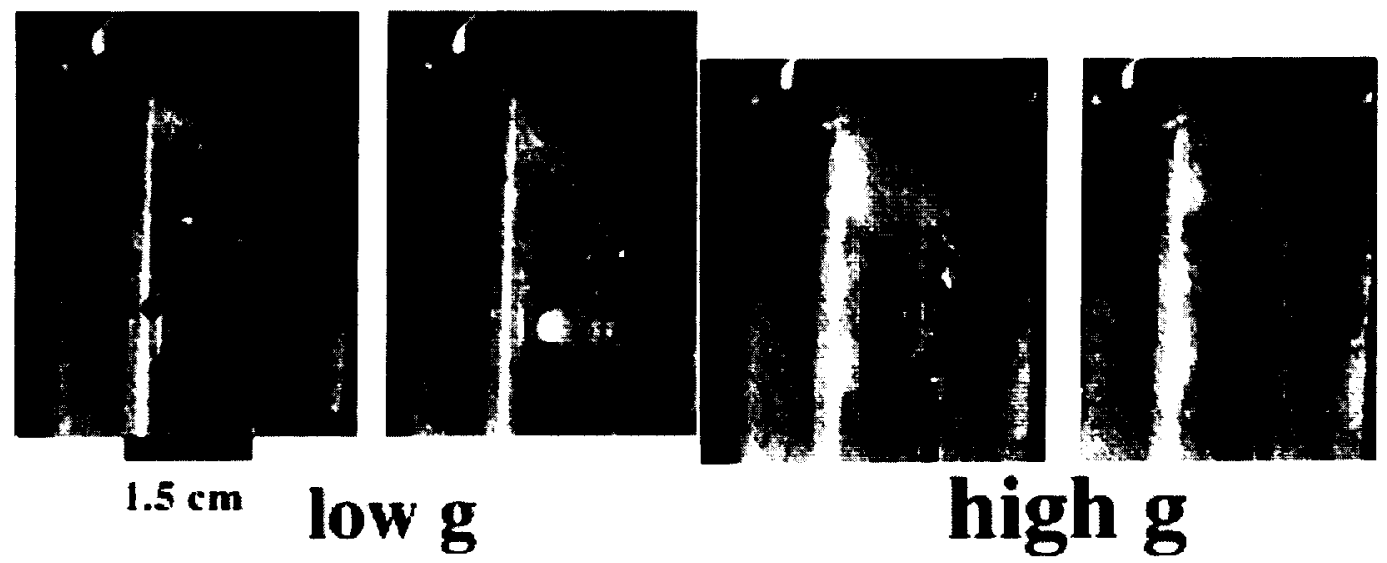

Figure 6. Fronts of benzyl acrylate polymerization in low and high $\mathrm{g}$. The fronts are propagating from the top of the images on down. Time between images is 12 seconds.

However, under low $g$ conditions, a single large bubble forms that can impede the front propagation, as can be seen in Figure 7. As the buoyant force is restored, the front grows around the bubbles, and only small bubbles are seen.

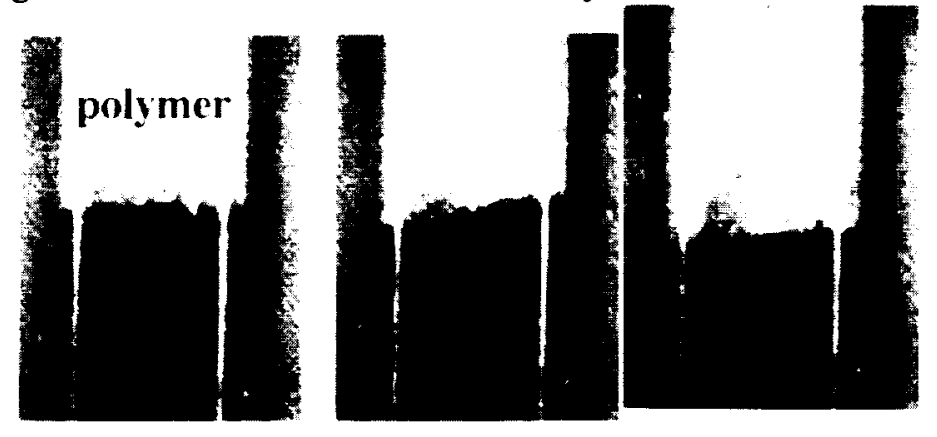

\section{low $\mathrm{g} \quad$ high $\mathrm{g}$}

Figure 7. Images of TGDMA frontal polymerization under low and high $g$ Time between images is approximately 10 seconds.

We propose this mechanism: Under $1 \mathrm{~g}$, the buoyant force holds a bubble up against the front, and so bubbles grow in low chains. However, in low $\mathrm{g}$ the bubble is free to move via surface tension-induced convection. Such motion allows bubbles to aggregate into a large bubble.

\section{Conclusions}

Frontal polymerization systems, with their inherent large thermal and compositional gradients, are greatly affected by buoyancy-driven convection. Sounding rocket experiments allowed the preparation of benchmark materials and demonstrated that methods to suppress the Rayleigh-Taylor instability in ground-based research did not significantly affect the molecular weight of the polymer. Experiments under weightlessness show clearly that bubbles produced during the reaction interact very differently than under $1 \mathrm{~g}$. Acknowledgments

We thank Dr. Robert Naumann for assistance in undertaking the Conquest I flight and for loaning hardware for the KC-135 flights. We thank Dr. Patton Downey of NASA's MSFC for support and assistance with the KC-135 flights. We are grateful to James Bridges and Steve Selph (USM) for design and fabrication assistance. Support for this project was provided by NASA's Microgravity Materials Science Program (NAG8- 
973), the Mississippi NASA EPSCoR program, the Air Force Office of Scientific Research and from Boston Optical Fiber, Inc.

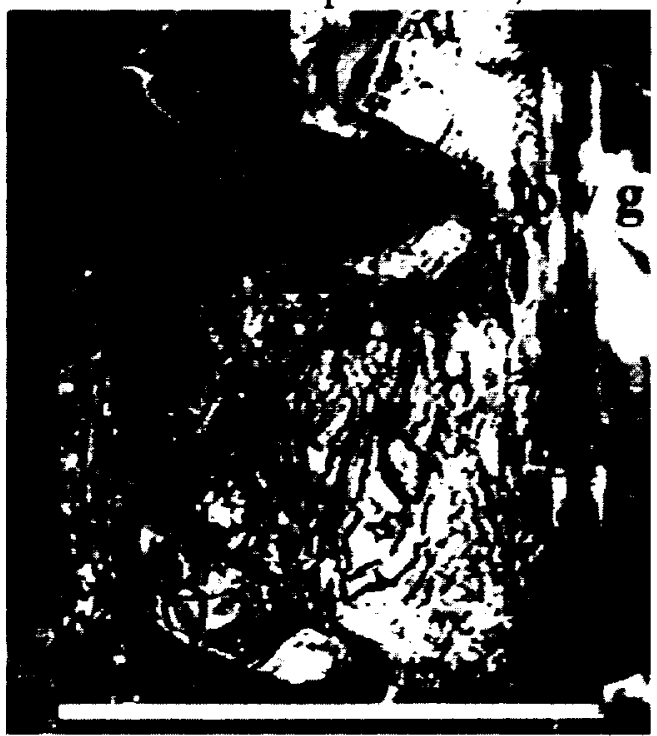

Figure 8. Image of TGDMA sample (from front in Figure 7) showing bubble aggregation under low g.

References

(1) Chechilo, N. M.; Khvilivitskii, R. J.; Enikolopyan, N. S. Dokl. Akad. Nauk SSSR 1972, 204, 1180-1181.

(2) Chechilo, N. M.; Enikolopyan, N. S. Dokl. Phys. Chem. 1975, 221, 392-394. Chechilo, N. M.; Enikolopyan, N. S. Dokl. Phys. Chem. 1976, 230, 840-843. Davtyan, S. P.; Zhirkov, P. V.; Vol'fson, S. A. Russ. Chem. Rev. 1984, 53, 150163.

(5) Pojman, J. A. J. Am. Chem. Soc. 1991, $113,6284-6286$.

(6) Pojman, J. A.; Craven, R.; Khan, A.; West, W. J. Phys. Chem. 1992, 96, 74667472.

(7) Pojman, J. A.; Willis, J.; Fortenberry, D.; Ilyashenko, V.; Khan, A. J. Polym. Sci. Part A: Polym Chem. 1995, 33, 643-652.

(8) Pojman, J. A.; Nagy, I. P.; Salter, C. J. Am. Chem. Soc. 1993, 115, 11044 11045.

(9) Pojman, J. A.; Ilyashenko, V. M.; Khan, A. M. J. Chem. Soc. Faraday Trans. 1996, 92, 2825-2837.

(10) Khan, A. M.; Pojman, J. A. Trends Polym. Sci. (Cambridge, U.K.) 1996, 4, 253-257.

(11) Pojman, J. A.; Khan, A., M.; West, W. Polym. Prepr. Am Chem. Soc. Div. Polym. Chem. 1992, 33, 1188-1189.

(12) Rayleigh, J. W. Scientific Papers, ii; Cambridge University Press: Cambridge, 1899.

(13) Taylor, G. Proc. Roy. Soc. (London) 1950, Ser. A. 202, 192-196.

(14) Chechilo, N. M.; Enikolopyan, N. S. Dokl. Phys. Chem. 1974, 214, 174-176.

(15) Garbey, M.; Taik, A.; Volpert, V. Preprint CNRS 1994, 187, 1-42.

(16) Volpert, V. A.; Volpert, V. A.; Garbey, M.; Pojman, J. A. in Gas-Phase Chemical Reaction Systems: Experiments and Models 100 Years after Max Bodenstein; Wolfrum, J.; Volpp, H.-R.; Rannacher, R. Warnatz, J.,Ed., Springer Berlin: Heidelberg, 1996; pp 309-317.

(17) Bowden, G.; Garbey, M.; Ilyashenko, V. M.; Pojman, J. A.; Solovyov, S.; Taik, A.; Volpert, V. J. Phys. Chem. B 1997, 101, 678-686.

(18) McCaughey, B.; Pojman, J. A.; Simmons, C.; Volpert, V. A. Chaos in press

(19) Chekanov, Y.; Arrington, D.; Brust, G.; Pojman, J. A. J. Appl. Polym. Sci. 1997, 66, 1209-1216.

(20) Pojman, J. A.; Willis, J. R.; Khan , A. M.; West, W. W. J. Polym. Sci. Part A: Polym Chem. 1996, 34, 991-995.

(21) Pojman, J. A.; Khan, A. M.; Mathias, L. J. Microg. sci. technol. 1997, X, 36-40. 